\title{
A methodology for connecting User Centered Design (UCD) with Eco-design. The possibility of migration of products to services based on the user acceptance
}

\author{
Rodea Chávez Alejandro ${ }^{\mathrm{a}}$ and Lucila Mercado Colin ${ }^{\mathrm{b}}$ \\ ${ }^{a}$ Industrial Design Posgrade, National Autonomous University of Mexico. Universidad 3000, Ciudad \\ Universitaria, Coyoacán, C.P. 04510, Mexico City 56220837 \\ ${ }^{\mathrm{b}}$ Design Theory and Process Departament, Metropolitan Autonomous University-Cuajimalpa, Constituyentes \\ 1054, Lomas Altas, Miguel Hidalgo, C.P.11950, Mexico City 91776650 EXT. 6947, 6937
}

\begin{abstract}
The consumer products generation is one of the main engines that fuel the planet's environmental problems, reduction of environmental impacts associated with the products has been studied from various aspects between them, the supply of products for public consumption instead of private, seeking to meet the needs of the community by establishing programs for sharing single product. It has been detected a problematic issues linked to this strategy, where the user acceptance of this new way of living together with the products must be achieved. The arguments here presented seek to identify user perception of such proposals and their possible acceptance throughout strategies from the User Centered Design (UCD).
\end{abstract}

Keywords: design for dematerialization; needs satisfactors; sharing products; public consume products; sustainability paradigm

\section{Introduction}

Designing is the action to propose and implement objects and elements, in anticipation of the needs of other individuals come to have, it develops the ability to think up and simulate the problems before attempting to manufacture. This preliminary study of the way the objects will have, is a creative process known as design [3].

Thus the design of a product involves the conceptualization of different facets or perspectives of a problem.

Sustainability is a broad and complex term, with range of economic, social and environmental intimately intertwined in the daily life of the world's total population. A problem of this magnitude requires from all disciplines and human activities to question it selves how to make and act in society, as well as which are their deepest goals and objectives.

Particularly, to address the design of needs satisfactors, products or services, several proposals have emerged ranging from methodologies to focus on particular features (DfX), whether technical, economic or environmental topics are tackled. Specifically at the Eco-design or Design for Environment (DfE), although fragmentary, focus its efforts on the aspects of greatest environmental impact. For example, one of many strategies that emerged from Eco-design is dematerialization of products, which besides referring to the downsizing of products or objects, it also includes the replacement of a physical product by intangible ones (services). The concept... Sharing products, assumes that when several people use the same product without actually belonging them, the product is used more efficiently. [2]

apdi_2@posgrado.unam.mx ${ }^{\mathrm{b}} 1 \mathrm{mercado@correo.cua.uam.mx}$ 
By proposing the creation of satisfiers based on no longer private consumer products but public ones, a concept closely linked to the service economy or functional economy, it emerge the need to assess the acceptance or perception of the user of such products in order to know the implications of this change of type of use of products, from private to public, and target opportunities for improvement such design proposals refer, and simultaneously avoiding the possible reasons for rejection or detachment of such proposals.

...it will be important to replace the private consumption of goods with public consumption, the consumption of services, or even minimal or no consumption when possible. By increasing support of public parks, libraries, transit systems, and community gardens, much of the unsustainable consumption choices today could be replaced by sustainable alternatives-from borrowing books and traveling by bus instead of by car to growing food in shared gardens and spending time in parks...Considering the social and ecological costs that come with consumerism, it makes sense to intentionally shift to a cultural paradigm where the norms, symbols, values, and traditions encourage just enough consumption to satisfy human well-being while directing more human energy toward practices that help to restore planetary wellbeing . [6]

While laudable and desirable, that mentioned change of paradigm, from private to public, from product to service, can lead to problems of users acceptance when migrating their now private satisfactors, to products and / or public services, taking away of them the absolute control of how to use or dispose it, atomizing such control in multiple and varied users, with also diverse ways of life and habits.

This raises the need for integration methodology based on User-Centered Design (UCD) and those of eco-design for the identification of these problems by allowing increasing the likelihood of success on the appropriateness of various satisfiers.

\section{User Centered Design (UCD)}

UCD is a broad term. Is a methodology to describe design processes to promote a real approach of design teams to end-users, so, users influence how a design takes shape, because their own necessities, limitations, possibilities and expectations are taken into account. By applying UCD, users are involved one way or another.

Currently, designers have enriched their work with a number of important insights that promotes a closer approach to the people who should use products. This can be interpreted in different ways, from analyzing only the attitude of the users when interacting with products, to the integration of users to the development groups. Such situation has increased the knowledge designers have about users, their motivations and needs, positively impacting the search of efficient and effective processes, and more satisfactory products, easily to use for different types of users.

Each of these approaches emphasizes a particular people's dimension of interest, whether cognitive, affective or physical performance, and so on. To that end should be applied methods and techniques which allow obtaining qualitative and / or quantitative data. However, despite their differences these views share a number of characteristics that allow grouping them under the concept of UCD.

Through UCD it could be identified the followingcharacteristics:

- Users Active participation. A clear understanding of users and the requirements of the tasks: to have a real knowledge of the context in which users carry out their activities.

- Appropriate allocation of function between users and technology: Demands of user to objects are considered and vice versa. - Iterative design solutions: consider the use of prototypes to evaluate the interaction, allowing feedback [7]. This feature allows carrying out several cycles in which the products evaluation provides useful preliminary information as feedback to the design team.

- Multidisciplinary Design Team: The user-centered development is collaborative and gains when professionals participate in different area related to the process 
tion with objects during the development of activities in specific application environments. - It studies the capabilities, limitations and needs of users in their physical, cognitive, emotional, social dimensions based on the understanding of the user's activities with such products. - It allows getting information for making decisions, based on the needs, goals, attitudes, motivations, capabilities and limitations of users. - It integrates end-users in various stages of project development.

- It evaluates the results of those designed products. UCD can generate efficient and effective systems that result in satisfactory and useful products for different types of users and to provide conditions which reduce or eliminate potentially negative impacts on the objectives of people. Then, it is important to consider several factors: the physical differences of users, their motivations, expectations, previous experiences, the type of activities carried out, the characteristics of the objects that mediate their activities and the specific environment in which such activities are carried out. Not reviewing these factors can turn this relationship into a vehicle of negative experiences that promote frustrations, accidents, injuries, cumulative stress and waste of time and / or money.

User-Centered Design has as one of its objectives, to identify interaction problems in the studied systems to aid in decision making in the design process. For identifying those problems, User-Centered Designers have to set goals, some of which are shown in figure 1:

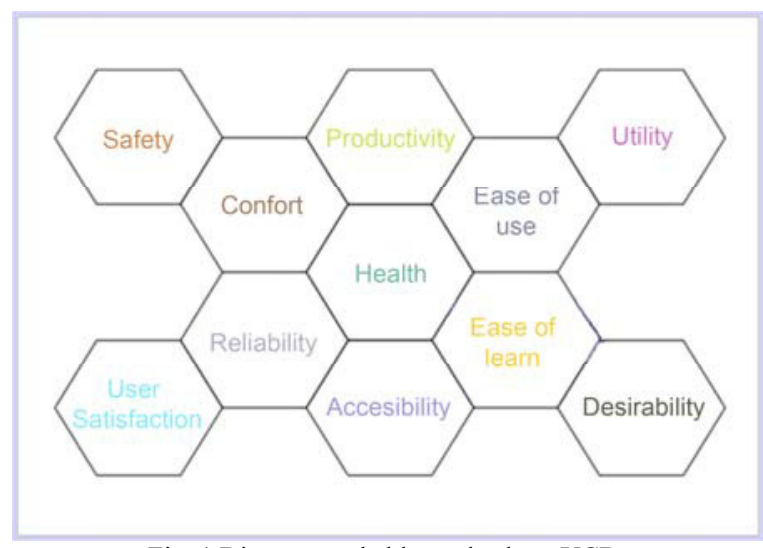

Fig. 1 Diverse reachable goals along UCD.

\section{Ecodesign}

On the other hand, from the standpoint of Ecodesign (or DfE), there are multiple aspects linked to the generation of products that designers should pay attention because the environmental problematic, but perhaps there are two major areas where the Ecodesign strategy may differ, such are the products design and production processes design.

Although both processes of design are closely linked, it is important to detect some essential differences.

While in product design process it is planned the performance of an object, the user interaction, the shape and size of objects for that purpose, and of course, the materials and processes of manufacture to build it, the design production processes focuses on how a material can be transformed to achieve particular products. Some of the aspects highlighted from the Eco-design perspective in the design production process are energy efficiency, reduction of leakage of materials, quality control or minimization of pollutants emissions. ${ }^{1}$

Obviously, both areas of design touch each other, and are interdependent to a large extent, but it is also clear differences among that, although cause are serving different stages of the life cycle of products or materials flow.. ${ }^{2}$

\section{Eco-design and UCD coincidences}

As mentioned before, just as in Eco-design, many routes have been differentiated from those ergonomics discipline meets, including the starting point of the same...Ergonomists often work in particular economic sectors or application domains [4]...around common technical and research interests[5] as aerospace systems, aging, cognitive engineering and decision making and so on.

Again, as we have seen on Eco-design issues, ergonomics could be seen from two specific but complementary points of view: one industrial or ocuppational in which -just to mention two- working related problems or cumulative disorders are taken into account and another, which emphasizes usability and user's emotional relationship with consumer products.

\footnotetext{
${ }^{1}$ For a deeper view of this topics, refer to Joseph Fiksel, Design for Environment, A guide to Sustainable product development. Mc Graw Hill, 2009.

2 See The Story of Stuffs Project. http://storyofstuff.org/index.php
} 
If we overlap both mentioned Eco-design foci or concerns (products and processes) we could find similarities with the ergonomics ones: occupational and consumer products.

If taken as true this classification, should also be considered that the objectives sought in the design of processes are very close to those of occupational ergonomics, and evidently something similar happens with design of products and consumer products of both disciplines.

Perhaps attending at these similarities, may establish methodologies and strategies to address together both approaches from the brief: the eco-design and the User-centered design. For example, Bhamra and Lofthouse have reported the application of various user-centered techniques in order to prevent ecodesigned products to be poor or inadequately used.

The development of the brief is always crucially important to any design project. The brief outlines any important issues for consideration, determines what tasks need to be carried out, stipulates where responsibility lies and details the time frame. It is effectively the blueprint for the project and often the basis for any financial agreement. To be effective, sustainable design considerations need to be integrated into design practice in the same way as ergonomics, styling, manufacturing considerations and as such need to be reflected in the brief . [1]

In the same text, they also reflect on how the design vision for the environment can evolve into a more systemic approach based on problem solving; this question is also addressed from the UCD.

It is also important to acknowledge the comments made by Brezet in 1997 (taken from Bhamra) where a 4-level of innovation to improve eco-efficiency was modeled, and where the greatest impact on this indicator was on innovation of systems, (above the functional innovation, redesigning products and product improvement,respectively).

In such a system innovation, though, leads to greater complexity and requires much more time for its establishment, it is possible to achieve higher levels of environmental, social and business improvement. Again, UCD is seen as a valuable tool to address the complexity of such required innovations.

Finally, the approach to sustainable development through User-Centered methods, have already been exposed by many authors, although expressing a timely manner how to use those in identifying various features of the user, perhaps is it necessary to emphasize that both User-Centered methodologies and as those of Eco-design must be used together, taking advantage of its similarities in the objectives pursued, and this way evolving from being specific objective methods or tools, to incorporate ethical positions that best of each of them, delving into the multi-pronged approach involved in the development of products or services, and moreover, going from focusing only on certain environmental or technological features, or otherwise, just seeking for user's resources and demands, to a more holistic vision, aimed at the sustainable paradigm.

\section{References}

[1] Bhamra Tracy, Lofthouse Vicky. Design for sustainability. A practical approach. Ed. Gower. Hampshire 2007.

[2] García Parra Brenda. Ecodiseño. Nueva herramienta para la sustentabilidad. Designio, México DF.2008.

[3] Simón Sol Gabriel, La trama del Diseño. Por qué necesitamos métodos para diseñar. Ed Designio, México 2010

[4] International Ergonomics Association web page http://www.iea.cc/01_what/What \%20is\%20Ergon omics.html consulted on Sept30th2011.

[5] Human Factors and Ergonomics Society http://hfes.org/web/TechnicalGroups/technical.html consulted on Sept 30th2011

[6] State of the world2010.Transforming Cultures From Consumerism to Sustainability. The WorldWatch Institute. 2010.

[7] ISO 9241-210 - Ergonomics of Human-system interaction. 